\title{
Quality Parameters Needed for Bee Products used in Apitherapy
}

\author{
Ştefan STÂNGACIU1 ${ }^{1}$, Liviu Al. MĂRGHITAŞ, Daniel DEZMIREAN, Victorița BONTA², Rodica MĂRGĂOAN², \\ Otilia BOBIŞ²* \\ ${ }^{1}$ Apitherapy Consulting \& Trading International Ltd. \\ ${ }^{2}$ Department of Apiculture and Sericulture, University of Agricultural Sciences and Veterinary Medicine \\ Cluj-Napoca, Manastur st. 3-5, 400372, Cluj-Napoca, Romania \\ *Corresponding author, email: obobis@usamvcluj.ro
}

Bulletin UASVM Animal Science and Biotechnologies 72(1) / 2015

Print ISSN 1843-5262; Electronic ISSN 1843-536X

DOI:10.15835/buasvmcn-asb:10561

\begin{abstract}
Apitherapy represents the utilization of bee products for preventing and curing a series of illnesses and also the promotion of a healthy life style through consumption of these products. Due to the fact that apitherapy is a part of medical science, bee products used for this purpose must have a certain quality, namely, they must possess a series of biologically active compounds that will help in the healing process. This study aims to show the "quality standards" for bee products used in apitherapy. Different samples of honey, propolis, bee-pollen, bee bread and royal jelly were analyzed for their physico-chemical parameters as well as for their active compounds, specific for each matrix. Standard methods were adapted in the lab for each matrix, using spectrophotometric and chromatographic determinations. Physico-chemical analyses of honey, bee-pollen, bee bread, propolis and royal jelly were in accordance with literature results. High amounts of flavonoids and phenolic acids were quantified in propolis tincture, bee pollen, bee bread, royal jelly and honey. Royal jelly samples were proved to be authentic and have a high amount of 10-hydroxydecenoid acid, a compound with high antioxidant and antibacterial activity.
\end{abstract}

Keywords: apitherapy, bee products, ingredients, quality

\section{INTRODUCTION}

The most important bee products are honey, bee-pollen, beebread, royal jelly, propolis, bee-venom and wax. These products have different roles in the bee family and in human nutrition. Man uses honey, bee-pollen, beebread and royal jelly mainly as food supplements and propolis and bee venom as treatment in different diseases, due to their high biological activity (Bobiș et al. 2010).

Honey is the most important bee product, both quantitatively and economically. It is also the first bee product used by man for ages. Honey consists generally of sugars and water (approximately $90 \%$ ), while the rest of the composition is made up of enzymes, minerals, aminoacids, organic acids, polyphenols and other substances (Perez et al., 2007; Mărghitaş et al. 2009). As nectar is the main raw material for producing floral honey, its chemical composition in biologically active compounds depends on numerous factors, such as botanical origin, as well as the climatic and geographic conditions where the honey is produced.

Honey always "borrows" the functional properties of the plant where the nectar and pollen are collected by the bee. It is generally known that polyphenols (secondary metabolites from plants) are one of the main compounds responsible for the biological activity of honey.

Propolis, or bee glue, is an important bee product, with extensive utilization in conventional medicine and in apitherapy. The chemical 
composition of propolis consists of different resins and vegetal balms, etheric oils, macro and microelements, flavonoids, bee secretions and wax. Romanian propolis is considered to be a poplar type propolis, because the main plant species is represented by poplar buds. The main class of chemical compounds giving the bioactive properties of propolis are polyphenols and especially flavonoids (Bankova et al., 1997) and fatty acids (Polyakov et al., 1988).

Bee pollen is a mixture of flower pollen, nectar, and bee secretions, of different colours, depending on the floral origin. Bees collect pollen to prepare bee bread, the proteic food of the hive. Sugars from pollen are glucose, fructose and sucrose, but also starch and cellulose from the flower pollen. Bee pollen is very rich in vitamins (B group, but also high amounts of $\mathrm{C}$ vitamin), in freshly collected bee pollen, minerals ( $\mathrm{Zn}, \mathrm{Ca}, \mathrm{Mg}, \mathrm{K}, \mathrm{Na}$ ), or carotenoids, accounting for the wide range of colors (yellow, orange, red), or anthocianins accounting for the violet colour. An important part of the chemical composition is represented by unsaturated fatty acids (omega 3 and omega 6) (Yang et al., 2013; Mărgăoan et al., 2014).

Because the bees rarely consume pollen as it is collected from flowers, in the hive this is converted to bee bread, a fermented product, made by the bees in order to be more available for own consumption.

This process take place naturally in the hive due to the bacterial loading of the pollen, the high temperature in the hive, the enzymes present in the pollen and the added lactobacilli from bee stomach and uncapped honey cells. By fermentation, pollen exine is broken and all the components from pollen became easy assimilables. Bee bread represents the lipid and protein source of the bee food.

Royal jelly is a secretion of worker bees, used for feeding bee larvae in the first three days of life and feeding the queen for its entire life. This substance is really a "royal" product, because it contains all the chemical compounds that are needed by an organism in order to grow and develop, to gain strength and have a long life.

Water content in royal jelly is high (60-70\%), this being the bee product with the highest water content, its dry weight consisting of sugars, proteins, lipids, fatty acids, aminoacids, vitamins, enzymes and hormones. Proteins and peptides are the main substances of dry weight. Free aminoacids consist mainly of proline and lisine. Fatty acids are the main fraction of the lipid class, followed by neutral lipids, sterols and hydrocarbons.

Organic acids have generally 8 or 10 atoms of carbon, the most important fatty acid being 10-hydroxidecenoid acid, which is a marker of authenticity. This compound has a high antibacterial activity (Garcia-Amoedo and Almeida-Muradian, 2009; Bărnuțiu et al. 2011), contributing to the small bacterial load of the product.

Apitherapy uses bee products to prevent and heal certain illnesses and to promote a healthy lifestyle with the help of these products. The term "apitherapy" derives from apis, meaning bee, and therapy, meaning treatment. Apitherapy claim to be effective against different diseases, from arthritis and chronic pain, to serious illnesses, like cancer and stroke. It is true that there is not much scientific evidence to support many of the claims of apitherapists, but apitherapy remains one of the most important parts of alternative medicine.

In order to be used in apitherapy, all bee products must have certain characteristics, well known chemical composition and above all, must be free of any contaminants.

The aim of the present paper is to establish the main characteristics needed for bee products used as supplements and adjuvants in apitherapy, or ingredients in developing new products or medicines.

\section{MATERIALS AND METHODS}

The research was carried out in the Laboratory for Quality Control of Bee Products and Bee Diseases in the University of Agricultural Sciences and Veterinary MedicineCluj-Napoca, investigating different samples of honey, propolis, bee pollen, beebread and royal jelly. The physicochemical parameters were determined according to Romanian and International Legislation for bee products or food ingredients.

Physicochemical analyses for all bee products were carried out following standard methods or original methods for each product.

Sugar profile for honey, pollen, bee bread and royal jelly was determined by high performance liquid chromatography (HPLC) with refractive 
index detection, following the method described in International Honey Commision Methods (http://www.ihc-platform.net/ihcmethods2009. pdf), adapted in the laboratory for every bee product. HPLC Shimadzu system consists of an LC-10AD pump, DGU-14A degasser, SIL-10AV VP auto sampler, RID-10A refractive index detector, thermostatted at $30^{\circ} \mathrm{C}$ with CTO-10AS VP temperature controller of separation column (Altima Amino $100 \AA \AA 5 \mu \mathrm{m}, 250 \mathrm{~mm} \times 4.6 \mathrm{~mm}$ ) with a mixture of acetonitril/water as mobile phase with $1.3 \mathrm{ml} / \mathrm{min}$ flow rate. For the quantification of main sugars, a calibration curve in the range $4-0.5 \mathrm{~g} / 100 \mathrm{~g}$, with regression coefficient of $\mathrm{R}^{2}=0.9982$ for a mixture of 9 standards (glucose, fructose, saccharose, trehalose, maltose, turanose, isomaltose, erlose, melezitose) was used. Results were expressed in $\mathrm{g} / 100 \mathrm{~g}$ bee product.

The content of total lipids (or wax) of pollen, bee bread, propolis and royal jelly was determined using Soxhlet method (Soxtherm, Gerhardt, Germany), using an adapted method from literature (Antinelli et al., 2002; AlmeidaMuradian et al., 2005).

Protein content of pollen, bee bread, royal jelly was determined by Kjeldahl digestion, distillation and titration, following an adapted method of Lujerdean and Varga (2002).

Royal jelly's authenticity parameter (10-hydroxydecenoid acid - 10-HDA) was determined by HPLC with PDA detection (Liu et al., 2008).

Results for all determinations were expressed as mean of three independent determinations \pm standard deviation (Microsoft Excel, 2010).
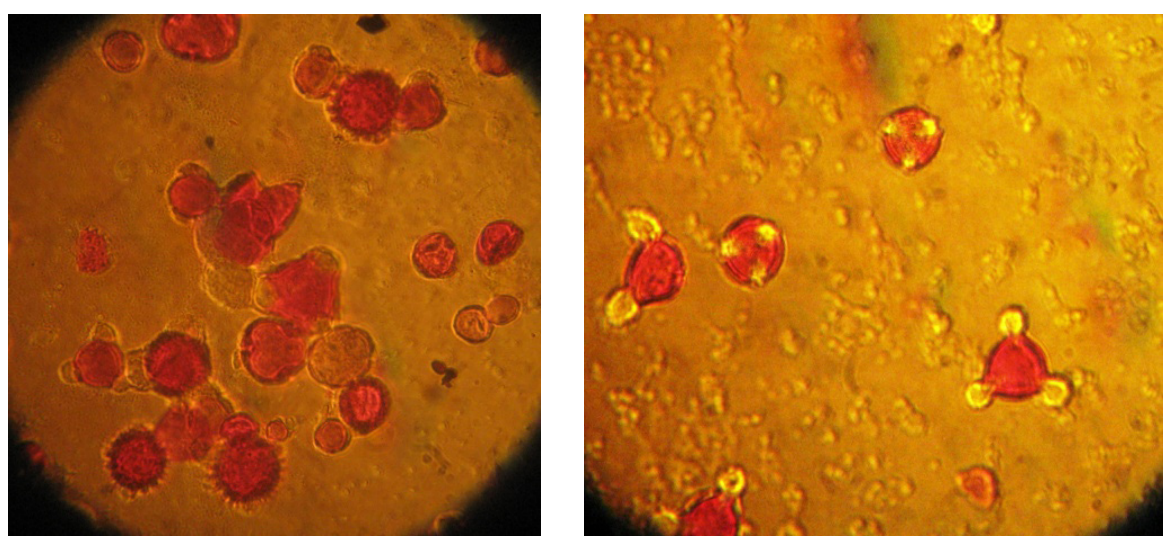

A
In order to see the biological activities of the analysed bee products, total phenols and total flavonoids were also determined. The methods used for these determinations were developed in the lab, following literature studies adequate for each bee product.

All bee products were checked for any contaminants: antibiotics, heavy metals, pesticides and acaricides. Different GC, atomic absorbtion and HPLC techniques were used for this matter (unpublished data).

Microbiological and bacteriological parameters determined were total number of aerobic germs (TGN) and number of yeasts and moulds. TGN represents the number of microbial colonies grown on agar media after inoculation and incubation with the analysed sample.

All chemicals and reagents were found analytically pure. The experimental data were expressed as mean values \pm standard deviation SD. Statistical differences were estimated among different samples (honey, propolis, pollen, beebread and royal jelly) at $\mathrm{p}=0.05$.

\section{RESULTS AND DISCUSSION}

In the present study, samples of black locust and multifloral honey were analysed, due to the fact that one type remains for a long period of time uncrystallised, and may be used in apitherapy as ingredient in different formulations, or may be applied on open wounds, and the other type was chosen because of the high content of bioactive compounds present in the chemical composition. Different apitherapists consulted indicated these two honeys for our study (Fig.1).

Fig.1. Microscopic image of pollen sediment from multifloral honey

(A) and black locust honey (B) 
Pollen samples were freshly harvested in 2014 and immediately placed at $-18^{\circ} \mathrm{C}$, to preserve all nutrients and bioactive compounds and also to prevent spoilage of the samples. After palynological analysis, the samples were classified as multifloral having as predominant species willow (Salix alba), hawthorn (Crataegus monogyna), dandelion (Taraxacum officinale), rape (Brassica spp.) and fruit trees (Prunus spp.). Propolis samples were purchased directly from beekeepers, having been harvested with propolis collector. Royal jelly samples were also purchased from beekeepers and placed immediately at $-18^{\circ} \mathrm{C}$ to preserve bioactive compounds and spoilage.

Main physico-chemical characteristics for the tested bee products were in accordance with values stated by existing standards or literature studies. These determinations are made mostly when nutritional values must be established. For apitherapeutical use, bioactive compounds from bee products must be determined, as well as microbiological analyses conducted.

In all bee products, monosaccharide glucose and fructose are the main sugars, present in different concentrations, according to each product. The highest amount of fructose was determined in black locust honey (42.21\%), followed by multifloral honey (36.54\%). For bee pollen and beebread, fructose was found in lower concentrations (18.56 and $17.25 \%$ ), while in royal jelly, fructose was quantified as $6.16 \%$. The content of glucose in honey samples ranged between 29.34 and $37.64 \%, 17.86 \%$ in bee pollen and lower in beebread (11.54\%). Higher level of glucose towards fructose was found in royal jelly samples (6.67\%). Sucrose content may be an authentication parameter, as amounts higher than $5 \%$ are not allowed in bee products. Other disaccharides present in the analysed bee products were turanose, maltose, trehalose and erlose (Table 1).

Bee pollen, bee bread and royal jelly posess high amounts of proteins and different quantities of lipids (Table 2).

The highest quantity of phenolic compounds was found in propolis, followed by bee bread, bee pollen, royal jelly and honey (multifloral and black locust honey). Figure 2 present total polyphenolic

Tab. 1. Sugar spectrum for the analysed bee products

\begin{tabular}{ccccccccc}
\hline Sample & $\begin{array}{c}\text { Glucose } \\
(\%)\end{array}$ & $\begin{array}{c}\text { Fructose } \\
(\%)\end{array}$ & $\begin{array}{c}\text { Sucrose } \\
(\%)\end{array}$ & $\begin{array}{c}\text { Maltose } \\
(\%)\end{array}$ & $\begin{array}{c}\text { Turanose } \\
(\%)\end{array}$ & $\begin{array}{c}\text { Trehalose } \\
(\%)\end{array}$ & $\begin{array}{c}\text { Erlose } \\
(\%)\end{array}$ & $\begin{array}{c}\text { Total } \\
\text { sugars } \\
(\%)\end{array}$ \\
\hline $\begin{array}{c}\text { Black locust honey } \\
(\mathrm{n}=5)\end{array}$ & $29.34 \pm 2.4$ & $42.21 \pm 3.1$ & $1.03 \pm 0.2$ & $1.44 \pm 0.1$ & $2.36 \pm 0.1$ & $0.52 \pm 0.0$ & $2.45 \pm 0.2$ & 79.35 \\
\hline $\begin{array}{c}\text { Multifloral honey } \\
(\mathrm{n}=5)\end{array}$ & $37.64 \pm 1.5$ & $36.54 \pm 2.6$ & $0.52 \pm 0.1$ & $1.62 \pm 0.2$ & $2.02 \pm 0.2$ & $1.13 \pm 0.1$ & $0.82 \pm 0.0$ & 80.29 \\
\hline Bee pollen (n=6) & $14.86 \pm 1.4$ & $18.56 \pm 1.6$ & $0.00 \pm 0.0$ & $0.09 \pm 0.0$ & $0.24 \pm 0.0$ & $0.05 \pm 0.0$ & $0.01 \pm 0.0$ & 33.81 \\
\hline Bee bread (n=5) & $11.54 \pm 1.2$ & $17.25 \pm 1.1$ & $0.00 \pm 0.0$ & $0.25 \pm 0.0$ & $0.82 \pm 0.1$ & $0.75 \pm 0.1$ & $0.02 \pm 0.0$ & 30.63 \\
\hline Royal jelly (n=5) & $6.67 \pm 0.2$ & $6.16 \pm 0.3$ & $0.51 \pm 0.1$ & $0.15 \pm 0.0$ & $0.29 \pm 0.0$ & $0.02 \pm 0.0$ & $0.09 \pm 0.0$ & 13.89 \\
\hline Results represent the mean of three determinations \pm standard deviation & & & & &
\end{tabular}

Tab. 2. Water content, total proteins, lipid content (wax for propolis) and 10-HDA content for the analysed bee product samples

\begin{tabular}{ccccc}
\hline Sample & Water content (\%) & Total proteins (\%) & Total lipids (\%) & 10-HDA (\%) \\
\hline Black locust honey $(\mathrm{n}=5)$ & $17.4 \pm 0.4$ & - & - & - \\
\hline Multifloral honey $(\mathrm{n}=5)$ & $18.2 \pm 1.1$ & - & - & - \\
\hline Bee pollen $(\mathrm{n}=6)$ & $20.6 \pm 1.4$ & $22.26 \pm 1.29$ & $4.96 \pm 0.67$ & - \\
\hline Bee bread $(\mathrm{n}=5)$ & $6.4 \pm 0.2$ & $17.25 \pm 1.1$ & $2.00 \pm 0.0$ & - \\
\hline Royal jelly $(\mathrm{n}=5)$ & $62.95 \pm 1.42$ & $12.70 \pm 0.53$ & $4.75 \pm 0.22$ & $2.15 \pm 0.8$ \\
\hline Raw propolis $(\mathrm{n}=3)$ & - & - & $22.4 \pm 1.3$ & - \\
\hline Results represent the mean of three determinations \pm standard deviation & &
\end{tabular}


content and total flavonoids, measured spectrophotometrically.

The highest quantity of total polyphenols was quantified in propolis tincture, followed by bee bread. This is an expected result because it is known that propolis has these bioactive properties due to the polyphenolic substances contained. Bee bread has also high amounts of phenols, more than bee pollen due to the fermentation processes to which pollen is subjected in the hive. In this way different classes of polyphenols are released from the pollen grains, which can be quantified spectrophotometrically. The polyphenols from royal jelly mainly came from the bee bread that nurse bees consume before producing this valuable product. Honey is expected to have the smallest quantity of polyphenols, because its main chemical composition is simple sugars and water. Propolis and bee pollen have the highest amount of flavonoids from the measured bee products, which is in accordance with literature data and own observations (Liu et al., 2008; Mărghitaş et al., 2009; Mărgăoan et al., 2014). The main phenolic compounds identified in honey and propolis samples were from the class of phenolic acids and flavonoids. From all tested bee products, the highest and most varied amount of phenolics were found in propolis tincture (Fig. 3).

The propolis samples analysed in this study confirm the latest literature studies (Bankova, 2005; Tomas-Barberan et al., 1993; Ozkul et al., 2005) and show that Romanian propolis can be classified as poplar type propolis.

Ferulic acid is considered one of the most important phenolic acid due to its antioxidant, antimicrobial, anti-inflammatory, anti-thrombotic and antitumor activities (Mussatto et al., 2007); p-coumaric acid is another important phenolic acid due to its antioxidant and chemopreventive properties (Mussatto et al., 2007).

Galangin, chrysin and pinocembrin represent important flavonoids in propolis tincture, with

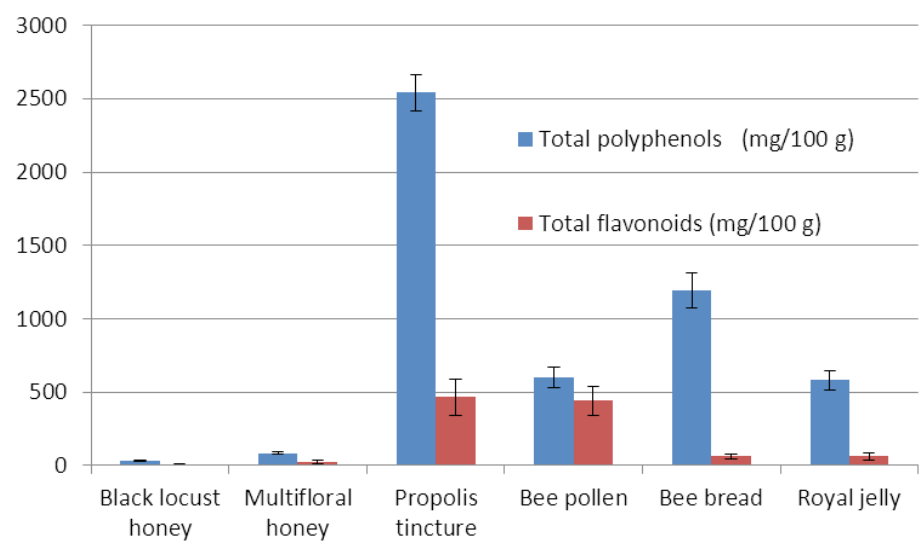

Fig.2. Biologically active compounds mesured from bee products

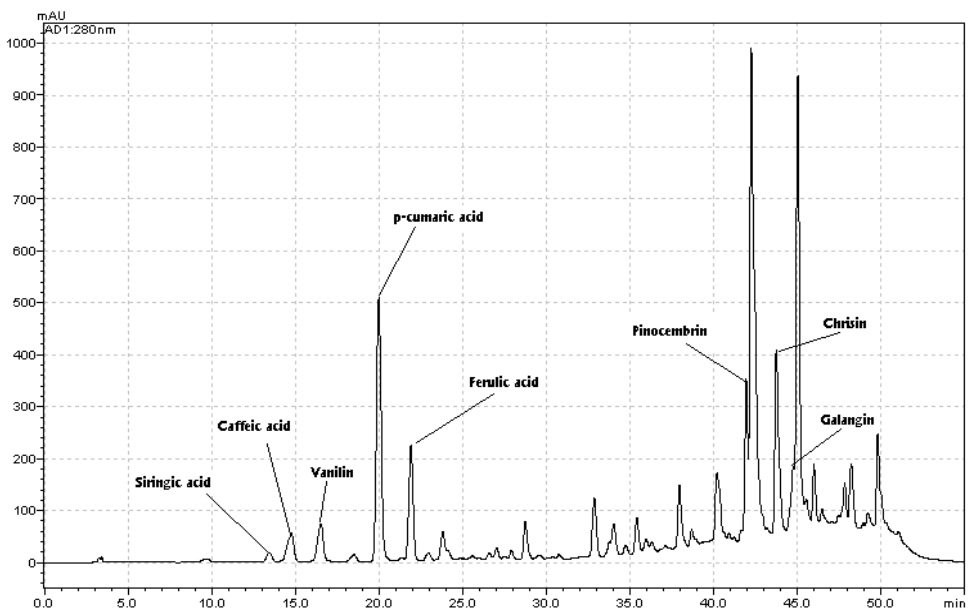

Fig 3. HPLC-PDA chromatogram of a $1 \%$ in ethanol $70 \%$ propolis sample 
numerous antioxidant, antimicrobial, anti-inflammatory and neuroprotective properties (Cushnie and Lamb, 2006; Dhawan et al., 2002; Shin et al., 2009).

Results in mycological and bacteriologic analyses for all bee products show under

$10^{-1}$ aerobic mesophilic germs $/ \mathrm{ml}$ of diluted samples; yeast and moulds were absent in bee collected pollen and beebread.

Pollen samples (crude pollen) present less than 50,000 aerobic mesophilic germs/ml diluted pollen and 100 yeasts and moulds $/ \mathrm{ml}$.

\section{CONCLUSIONS}

Bee products that are to be used in apitherapy must be authentic (in respect of chemical composition) and must possess high amounts of bioactive compounds, with biological properties. Romanian bee products, especially those tested in the present study, possess high amounts of bioactive compounds, with determined antioxidant or antimicrobial properties. The existence of accreditated laboratories which can perform these tests is of great help to all apitherapists, not to mention the consumers, the producers or retailers.

Acknowledgments. This research was partly supported by IEC SOP project RoBeeTech, no. 206/2010 and through the Partnerships in Priority Areas Programme - PN II, developed with the support of MEN - UEFISCDI, project no. 148/2014.

\section{REFERENCES}

1. Almeida-Muradian LB, Pamplona LC, Coimbra S, Barth OM (2005). Chemical composition and botanical evaluation of dried bee pollen pellets. J Food Comp Anal 18(1):105-111.

2. Antinelli JF, Zeggane S, Davico R, Rogone C, Faucon JP, Lizzani L (2003). Evaluation of 10-HDA as a freshness parameter of Royal Jelly. Food Chem 80:85-89.

3. Bankova V (2005). Chemical diversity of propolis and the problem of standardization, J Ethnophar, 100:114-117.

4. Bankova V, Christov R, Hegazi AG, Abd El Hady FK, Popov $S$ (1997). Chemical composition of propolis from poplar buds. Int Symp on Apitherapy, Cairo, Egypt

5. Bărnuțiu LI, Mărghitaş LA, Dezmirean DS, Mihai CM, Bobiş $O$ (2011). Chemical composition and antimicrobial activity of Royal Jelly - Review. Scientific Papers: Animal Sciences and Biotechnologies 44: 67-72.

6. Bobiş O, Mărghitaş LA, Dezmirean D. Bonta V, Mihai CM (2010). Beehive products: source of nutrients and naturally biologically active compounds. J Agroalim Proc Technol 16(2):104-109.
7. Cushnie TPT, Lamb AJ (2006). Assessment of the antibacterial activity of galangin against 4-quinolone resistant strains of Staphylococcus aureus, Phytomedicine 13:187-191.

8. Dhawan K, Kumar S, Sharma A (2002). Beneficial effects of chrysin and benzoflavone on virility in 2-year-old male rats, J Medicinal Food 5:43-48.

9. Garcia-Amoedo JH, Almeida-Muradian LB (2007). Physicochemical composition of pure and adulterated royal jelly. Quim Nova 30: 257-259.

10. Letizia CS, Cocchiara J, Lapczynski A, Lalko J, Api AM (2005). Fragrance material review on cinnamic acid, Food Chem Toxicol 43:925-943.

11. Liu JR, Yang YC, Shi LS, Peng CC (2008). Antioxidant properties of royal jelly associated with larval age and time of harvest. Altern Med Rev 13:330-333.

12. Lujerdean A, Varga A (2002). Metode şi tehnici de laborator în biochimie. Ed. AcademicPress, Cluj-Napoca

13. Mărgăoan R, Mărghitaş L, Dezmirean D, Dulf F, Bunea A, Socaci AS, Bobiș $O$ (2014). Predominant and secondary pollen botanical origin influence the carotenoid and fatty acid profile in fresh boneybee collected pollen. J Agric Food Chem 62:6306-6316.

14. Mărghitaş L, Dezmirean D, Moise A, Bobiş O, Laslo L, Bogdanov S (2009). Physico-chemical and bioactive properties of different floral origin honeys from Romania. Food Chem. 112: 863-867.

15. Molan PC (1999). Honey for the treatment of infection. Available: http://www.apitherapy.org/AAS/molan.html.

16. Mussatto SI, Dragone G, Roberto IC (2007). Ferulic and $p$-coumaric acids extraction by alkaline hydrolysis of brewer's spent grain, Industrial Crops and Products 25:231-237.

17. Ozkul Y, Silici S, Eroglu E (2005). The anticarcinogenic effect of propolis in human lymphocytes culture. Phytomedicine 12: 742-747.

18. Pérez RA, Iglesias MT, Pueyo E, Gonzalez M, de Lorenzo C (2007). Amino acid composition and antioxidant capacity of Spanish honeys. J Agric Food Chem 55:360-365.

19. Polyakov VV, Shukenova RZH, Orlov VK (1988). Fatty acids in propolis. Pchelovodstvo 10: 30.

20. Shin EK, Kwon HS, Kim YH, Shin HK, Kim JK (2009). Chrysin, a natural flavone, improves murine inflammatory bowel diseases. Biochem Biophys Res Comm 381:502507.

21. Tomas-Barberán, FA, Garcia-Viguera C, Vitolivier $P$, Ferreres F, Tomás-Lorente F (1993). Phytochemical evidence for the botanical origin of tropical propolis from Venezuela. Phytochemistry, 34:191-196.

22. Yang K, Wu D, Ye X, Liu D, Chem J, Sun P (2013). Characterization of chemical composition of bee pollen in China. J Agric Food Chem 61:708-718.

23. **http://www.ihc-platform.net/ihcmethods2009.pdf 